\title{
Modeling the Mechanical Response of a Dual-Phase Steel Based on Individual-Phase Tensile Properties
}

\author{
Paulina Alvarez ${ }^{1}$, Francisco Muñoz ${ }^{1}$, Diego Celentano ${ }^{2}{ }^{\circledR}$, Alfredo Artigas ${ }^{1}$, \\ Felipe M. Castro Cerda ${ }^{1}{ }^{(\mathbb{D}}$, Jean-Philippe Ponthot ${ }^{3}$ and Alberto Monsalve $1, * \mathbb{C}$ \\ 1 Departamento de Ingeniería Metalúrgica, Universidad de Santiago de Chile, Santiago 9170124, Chile; \\ paulina.alvarezs@usach.cl (P.A.); francisco.munozm@usach.cl (F.M.); alfredo.artigas@usach.cl (A.A.); \\ felipe.castro@usach.cl (F.M.C.C.) \\ 2 Departamento de Ingeniería Mecánica y Metalúrgica, Pontificia Universidad Católica de Chile, \\ Santiago 7820436, Chile; dcelentano@ing.puc.cl \\ 3 Department of Aerospace and Mechanical Engineering, University of Liège, 4032 Liège, Belgium; \\ JP.Ponthot@uliege.be \\ * Correspondence: alberto.monsalve@usach.cl; Tel.: +56-968-475-721
}

Received: 19 June 2020; Accepted: 29 July 2020; Published: 1 August 2020

\begin{abstract}
In this work, the engineering stress-strain tensile curve and the force-deflection bending curve of two Dual-Phase (DP) steels are modeled, combining the mechanical data of fully ferritic and fully martensitic steels. The data is coupled by a modified law of mixture, which includes a partition parameter $q$ that takes into account the strength and strain distributions in both martensite and ferrite phases. The resulting constitutive model is solved in the context of the finite element method assuming a modified mixture rule in which a new parameter $q^{\prime}$ is defined in order to extend the capabilities of the model to deal with triaxial stresses and strains and thus achieve a good agreement between experimental results and numerical predictions. The model results show that the martensite only deforms elastically, while the ferrite deforms both elastically and plastically. Furthermore, the partition factor $q^{\prime}$ is found to strongly depend on the ferritic strain level. Finally, it is possible to conclude that the maximum strength of the studied DP steels is moderately influenced by the maximum strength of martensite.
\end{abstract}

Keywords: Dual-Phase steel; ferrite; martensite; constitutive modeling

\section{Introduction}

The Dual-Phase (DP) microstructure consists of a mixture of soft and ductile ferrite and hard martensite. DP steel can be produced by either hot-rolling plus controlled cooling or via continuous annealing at the intercritical $\alpha+\gamma$ range. DP steels are widely applied by the automotive industry, principally due to its good strength/formability ratio.

The main mechanical and microstructural features of DP steels have been widely studied in the past years [1-3]. A large amount of literature on DP steels was published in those years. In the eighties, studies on the influence of process factors on the mechanical properties of DP steels were carried out by Furukawa and collaborators, finding that a two-stage cooling after the intercritical cooling produces martensite plus ductile ferrite [4]. Additionally, Shirasawa and Thomson studied the influence of hot band microstructure on strength of cold rolled DP steels [5]. In the nineties, Sugimoto and collaborators studied the stability of retained austenite in DP steels [6,7]. The fatigue life of DP steels was measured by Hashimoto and Pereira, who showed that a ferritic-martensitic steel had a better fatigue behavior than ferritic-pearlitic steel [8]. The mechanical behavior of Dual-Phase steels with different volume fraction of martensite was studied by Pouranvari, who found that when increasing the martensite volume 
fraction over $60 \%$, a decrease in the tensile strength is observed, a result that disagrees with the mixture law [9]. The stretch-flange-formability of DP steels was studied by Hasegawa et al. [10], who found that during hole-expanding, microcracks propagation depends on the quality of stretch-flange formability. At low formability, cracks propagate along the phase interfaces, while at high formability, cracks propagate through ferrite or martensite phases. Additionally, El-Sesy, investigating the influence of $\mathrm{C}$ and $\mathrm{Fe}_{3} \mathrm{C}$ on properties of DP steels, found that carbon in each phase plays an important role in mechanical behavior of each phase [11]. Recently, a complete review was published by Tasan and collaborators, focusing the work on microstructure changes during processing together with experimental characterization and numerical simulation of the mechanical behavior [12]. These authors divide the simulation works into three categories: predictions based on averaged properties, models consisting of microstructural features, and finally simulations related to local mechanical response. Related to mechanical properties, a strain accommodation phenomenon between ferrite and martensite during plastic deformation was acknowledged early $[13,14]$. This strain partitioning was measured via in situ mechanical testing combined with Digital Correlation Imaging (DIC) $[15,16]$ and X-ray tomography analysis [17]. The localization of a dislocation substructure in ferrite, which is reached by accommodating the strain in regions nearby martensite, is observed at different stages of tensile tests. The mixed nature of the deformation processes, characteristic of ferrite-martensite aggregates, has led the present authors to consider a model for describing the mechanical behavior of DP steel based upon the properties of the individual phases. The influence of microstructural variables on the deformation behavior of DP steels was studied by Jiang and collaborators, finding that refining the ferrite grain size and increasing the volume fraction of martensite, the yield stress and the strain hardening increased [18]. The effect of ultrafine ferrite grain size of about $2.7 \mu \mathrm{m}$ and an average martensite size island of about $2.9 \mu \mathrm{m}$ on the work hardening was studied by Pan et al. [19], who found superior mechanical properties attributed to the refinement. Additionally, an image-based calculation of stress-strain curve of the two-phase microstructure material was developed by Koyama, using specifically a modified version of the secant moduli method proposed by Weng [20]. The influence of strain rates on the deformation and fracture behavior of two DP steels was studied by Liang et al. [21], finding that the yield strength monotonically increases with strain rates whereas the behavior of the ultimate tensile strength, uniform deformation and post uniform elongation only exhibit a significant increase for high strain rate levels.

Related to modeling, many authors have contributed with different proposals. Tomota and Tamura studied the mechanical behavior of dual-phase steels, analyzing aspects such as the parameters controlling the mechanical properties, the different stages of the stress-strain curve, the work hardening, and the theories of deformation [22]. A theoretical model of the tensile work hardening behavior of Dual-Phase steels based on a partition parameter was developed by Lian and collaborators, where various volume fraction of martensite were modelled, finding two stages of work hardening during plastic deformation [23]. A micromechanical cell-based model for DP steels was developed by El-Abassy and Nemes, who used the single-phase parameter as unique input data for the model, obtaining results that show a good agreement between the experimental and numerical predictions, in terms of both stress-strain curve and strain hardening rate [24]. A micromechanical model based on the dislocation-based work-hardening model that considers multi-boundaries hardening was developed by Ren et al. [25], finding that the theoretical predictions for tensile tests showed a good agreement with the experimental results. A micromechanical model that explains the influence of martensite fraction on the $0.2 \%$ proof stress was developed by Liedl and collaborators, carrying out three-dimensional finite element simulations and showing that there exists a work-hardened ferrite zone that has influence in the initial flow behavior of the steel [26]. More recently, Evin et al. [27] modeled the yield strength, the uniform deformation and the true stress of DP steels based on both the volume fraction of secondary phases and the grain size of the ferrite grain. Crystal plasticity modeling was applied by $\mathrm{Xu}$ et al. [28] to describe the response of DP steels taken into account that the volume fractions of the constituent phases and the strain partitioning function could be obtained by tensile experiments. 
In accordance to the previous literature review, it is possible to conclude that predictive approaches for the tensile stress-strain curve are either (i) phenomenological models based on semi-empirical laws for the composite material, or (ii) physically based models which can treat the stress-strain curve as a summation of individual contributions. The present study develops the second (ii) strategy and considers that the mechanical behavior of the DP steels can be reasonably represented by the combination of the individual phases by a simple mixture law. Therefore, the aim of this work is to explore the possibilities and limitations of this constitutive model in describing the mechanical response of DP steels subjected to different loading conditions. Numerical simulations were carried out via an elastoplastic model proposed and implemented on an existing finite element-based code [29-32]. The model was validated by comparison with experimental measurements of two DP steels subjected to tensile and bending tests.

\section{Materials and Methods}

\subsection{Initial Material and Heat Treatments}

Five different steels were considered in the experimental campaign carried out in the present study. The first one is an ultra-low carbon (ULC) steel that was annealed at a temperature close to $\mathrm{A}_{1}$ and furnace-cooled to ensure the spheroidization of cementite. The second one corresponds to a medium carbon (MC) steel in the as-quenched condition. The other three were DP steels that consisted of low carbon steels that were subjected to an intercritical heat treatment to produce a microstructure consisting of different fractions of ferrite and martensite. The chemical compositions and parameters of the heat treatments are shown in Tables 1 and 2, respectively. The three heat treatments were carried out in an electric resistance furnace of temperature variability in the range of $\pm 2{ }^{\circ} \mathrm{C}$. The crust of decarburized material was machined out before sampling.

Table 1. Chemical composition (in wt.\%).

\begin{tabular}{cccccc}
\hline Steels & $\mathbf{C}$ & Si & Mn & P & S \\
\hline ULC-Ferrite & 0.070 & 0.010 & 0.260 & 0.016 & 0.010 \\
MC-Martensite & 0.440 & 0.160 & 0.750 & 0.020 & 0.030 \\
DP0 & 0.180 & 0.130 & 0.220 & 0.018 & 0.010 \\
DP1 & 0.048 & 0.023 & 0.417 & 0.027 & 0.0087 \\
DP2 & 0.172 & 0.0094 & 0.395 & 0.022 & 0.0090 \\
\hline
\end{tabular}

Table 2. Heat treatment parameters. HT and Ht are acronyms for holding temperature and holding time respectively.

\begin{tabular}{cccc}
\hline Steels & HT, $\left({ }^{\circ} \mathbf{C}\right)$ & Ht, (s) & Cooling \\
\hline ULC-Ferrite & 720 & 600 & Furnace \\
\hline MC-Martensite & 925 & 180 & Quench \\
\hline DP0 & 785 & 1800 & Quench \\
\hline DP1 & 810 & 300 & Quench \\
\hline DP2 & 800 & 900 & Quench \\
\hline
\end{tabular}

\subsection{Metallography}

The specimen preparation for metallographic observation was carried out via standard grinding and polishing procedure. The last polishing stage was performed with $1 \mu \mathrm{m}$ diamond paste. The etching used to reveal the microstructure in the as-polished surface was Nital 2\% v/v (a solution of $\mathrm{HNO}_{3}+$ ethanol). The imaging was performed on an Olympus BX51 optical microscope (Olympus, Tokyo, Japan) equipped with a ProgRes C3 digital camera (Jenoptik, Jena, Germany). The phase 
quantification was performed in the DP steels with the software Image Pro Plus (Version 6.0, Media Cybernetics, Rockville, MD, USA).

\subsection{Tensile, Bending and Hardness Tests}

The tensile properties of the studied steels were obtained by uniaxial testing using a 30-ton hydraulic Tinius-Olsen super L model testing machine (Tinius\&Olsen, Horsham, PA, USA), equipped with a linear variable differential transformer (Tinius\&Olsen, Horsham, PA, USA) and a digital data management system (HMTEST, Horsham, PA, USA). Cylindrical and rectangular samples were taken parallel to rolling direction. The dimensions of the samples and the procedure to run the tensile tests are specified in the ASTM E8 standard. The cross-head speed was $2.5 \mathrm{~mm} / \mathrm{min}$. The measurement of the strain was carried out with an extensometer attached to the gage length of each sample. A minimum of three samples were tested for each material.

On the other hand, a three-point bending test was carried out using the previous testing machine measuring deflection by means of a deflectometer, at a cross-head speed of $2 \mathrm{~mm} / \mathrm{min}$. Bending was stopped at $11 \mathrm{~mm}$ of deflection or when the sample breaks, obtaining the register of force and displacement. The dimensions of the DP1 samples were $150 \times 20 \times 0.6 \mathrm{~mm}^{3}$ and those of the DP2 were $150 \times 20 \times 3 \mathrm{~mm}^{3}$.

Finally, Vickers hardness tests were performed on a Struers Duramin micro hardness test machine (Struers, Copenhagen, Denmark). The values correspond to an average of 10 measurements under $1 \mathrm{Kgfload}$ for $15 \mathrm{~s}$.

\section{Thermodynamic and Kinetic Calculations}

To design the intercritical treatment to obtain the DP steels, the heat treatments were based on the calculation of equilibrium temperatures for each system. Such calculations were carried out using the software ThermoCalc (Version 4.1, database TCFE9, ThermoCalc AB, Solna, Sweden), database TCFE9. The $A_{1}$ and $A_{3}$ temperatures calculated for each steel are shown in Table 3. As an example, the heat treatment of the DP0 steel, which was selected in this work as the reference material to calibrate the heat treatment parameters, was designed to produce a specific fraction of austenite (martensite) of $\sim 40 \%$. To achieve this fraction, the ThermoCalc calculations predicted, for an equilibrium fraction of $\sim 45 \%$, a temperature of $785^{\circ} \mathrm{C}$. The temperature dependence of austenite fraction is shown in Figure 1a.

Table 3. Equilibrium temperatures $\left({ }^{\circ} \mathrm{C}\right)$.

\begin{tabular}{cccc}
\hline Steels & $\mathbf{A}_{\mathbf{1}},\left({ }^{\circ} \mathbf{C}\right)$ & $\mathbf{A}_{\mathbf{3}},\left({ }^{\circ} \mathbf{C}\right)$ & Martensite Volume Percent \\
\hline ULC-Ferrite & 718 & 871 & 0 \\
\hline MC-Martensite & 712 & 768 & 100 \\
\hline DP0 & 722 & 842 & 40 \\
\hline DP1 & 722 & 867 & 37 \\
\hline DP2 & 722 & 826 & 67 \\
\hline
\end{tabular}

Dictra calculations were performed in order to estimate the time for achieving a suitable austenite phase fraction. The design of the simulation includes the definition of a representative volume (RV), which considers the dimensions of the initial constituents (average diameter of the proeutectoid ferrite grains and the pearlitic colonies). Measurements on the initial microstructure yielded an RV value of $12 \mu \mathrm{m}$ length, considering a rectangular geometry. The martensite fraction in the DP steels was assumed to form from the transformation of austenite up to the final cooling implying, therefore, that the fraction of austenite formed during the heat treatment would determine the fraction of martensite. For the sake of simplicity, all the cementite in the initial microstructure was considered to transform instantaneously into austenite, which represents an initial fraction of $\sim 28 \%$. Previous studies on austenite formation [11] support the previous assumption, since the initial stage of austenite 
formation is very fast. The simulations were carried out at $785^{\circ} \mathrm{C}$ for $30 \mathrm{~min}(1,800 \mathrm{~s})$. The results are shown in Figure $1 \mathrm{~b}$. The calculated austenite carbon content after $1,800 \mathrm{~s}$ is $\sim 0.41 \mathrm{wt} . \%$, hence yielding a reasonable proximity to the carbon content of the MC steel (Table 2).

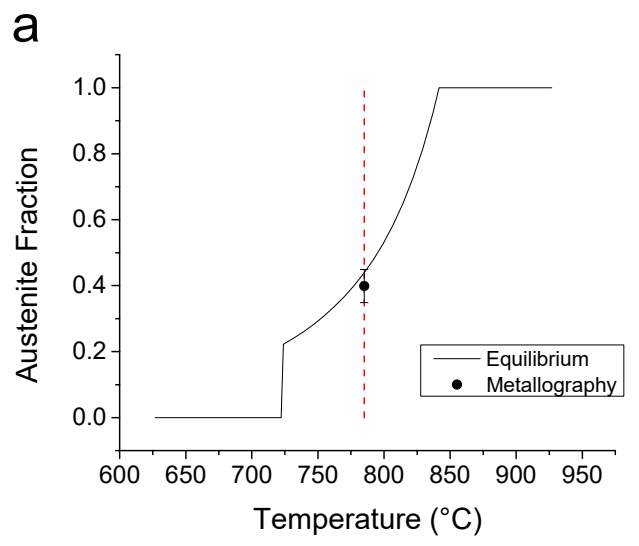

(a)

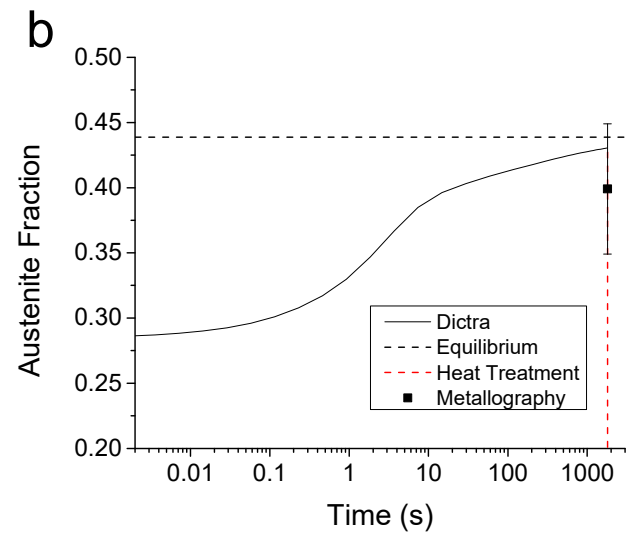

(b)

Figure 1. (a) Temperature dependence of the equilibrium fraction of austenite formed on heating and (b) calculation of the time dependence of the austenite formation at $785{ }^{\circ} \mathrm{C}$.

\section{Constitutive Model}

The constitutive model introduced in this section is a 3D extension of the uniaxial model developed by Lian et al. [23]. The Cauchy stress $\sigma$ and strain $\varepsilon$ tensors (as usual, boldface is used for tensors) are both defined via the law of mixtures as

$$
\begin{gathered}
\boldsymbol{\sigma}=V_{m} \boldsymbol{\sigma}_{m}+V_{f} \boldsymbol{\sigma}_{f} \\
\boldsymbol{\varepsilon}=V_{m} \boldsymbol{\varepsilon}_{m}+V_{f} \boldsymbol{\varepsilon}_{f}
\end{gathered}
$$

where $V$ : volume fraction and subscripts $m$ and $f$ stand for martensite and ferrite, respectively, such that $V_{m}+V_{f}=1$. Both ferrite and martensite phases are supposed to be homogeneous. The generalized stress transfer or strain partitioning coefficient $q$ relates stress and strain tensors as

$$
\sigma-\sigma_{f}=q\left(\varepsilon-\varepsilon_{f}\right) ; \sigma_{m}-\sigma_{f}=q\left(\varepsilon_{m}-\varepsilon_{f}\right)
$$

Alternative expressions written in terms of strain increments are proposed as

$$
\left(\bar{\sigma}-\bar{\sigma}_{f}\right) \dot{\varepsilon}=q^{\prime}\left(\dot{\varepsilon}-\dot{\varepsilon}_{f}\right) ;\left(\bar{\sigma}_{m}-\bar{\sigma}_{f}\right) \dot{\varepsilon}=q^{\prime}\left(\dot{\varepsilon}_{m}-\dot{\varepsilon}_{f}\right)
$$

in which $q^{\prime}$ is the strain rate partitioning coefficient and $\bar{\sigma}$ is the equivalent stress. From Equations (2) and (4), the martensite and ferrite strain increments can be written as

$$
\dot{\varepsilon}_{m}=\left(1+\frac{V_{f}}{V_{m}} \frac{\bar{\sigma}-\bar{\sigma}_{f}}{q^{\prime}}\right) \dot{\varepsilon} ; \dot{\varepsilon}_{f}=\left(\frac{\bar{\sigma}-\bar{\sigma}_{f}}{q^{\prime}}\right) \dot{\varepsilon}
$$

The stress-strain law for each component $i=m, f$ is given by

$$
\sigma_{i}=E_{i}\left(\varepsilon_{i}-\varepsilon_{i}^{p}\right)
$$


where $\boldsymbol{E}$ : isotropic elastic constitutive tensor and $\varepsilon^{p}$ : plastic strain tensor whose increment, according to the classical rate-independent plasticity theory, can be expressed as

$$
\dot{\varepsilon}_{i}^{p}=\dot{\lambda}_{i} \frac{\partial F_{i}}{\partial \sigma_{i}}
$$

where $\dot{\lambda}$ : plastic consistency parameter (computed according to standard concepts of the plasticity theory [33]); and F: plastic flow potential. In this framework, $F$ is also assumed to be the yield function such that no plastic evolutions occur when $F \leq 0$. In metal plasticity, a classical choice for $F$ is the von Mises function

$$
F_{i}=\bar{\sigma}_{i}-C_{i}=0
$$

such that the equivalent stress is given by $\bar{\sigma}=\sqrt{3 J_{2}}$, with $J_{2}$ being the second invariant of the deviatory part of $\sigma$, and the yield strength $C_{i}$ is assumed as

$$
C_{i}=C_{0 i}+K_{i}\left\langle\bar{\varepsilon}_{i}^{p}-\bar{\varepsilon}_{i}^{c}\right\rangle^{n_{i}}
$$

where $C_{0}$ is the yield stress of initial material; $\bar{\varepsilon}^{p}$ : the effective (or equivalent) plastic deformation (note that in this context, $\dot{\varepsilon}=\dot{\lambda}$ ); while $K$ and $n$ are the parameters aimed at characterizing the hardening behavior of the material. Furthermore, $\bar{\varepsilon}^{c}$ is the critical effective plastic strain accounting for the effect of Lüders' band formation, considered here as a perfectly plastic process, and \langle\rangle are the Macauley brackets (i.e., $\langle x\rangle=x$ if $x>0$ and $\langle x\rangle=0$ otherwise). Due to the absence of heterogeneous deformation and Lüders' bands, the model simply considers the Hollomon law with a critical deformation equals to zero.

As already pointed out by Lian et al. [23], the strain partitioning coefficient $q$ depends on both the martensite content and the deformation of the composite material. In the present work, the strain rate partitioning coefficient $q^{\prime}$ is defined, for a given composition, in terms of the effective plastic deformation also given by the law of mixtures $\bar{\varepsilon}^{p}=V_{m} \bar{\varepsilon}_{m}{ }_{m}+V_{f} \bar{\varepsilon}_{f}^{p}$. As shown in Section 4, the function $q^{\prime}\left(\bar{\varepsilon}^{p}\right)$ derived from the experimental stress-strain curve of the steel decreases with the level of deformation.

The presented mechanical formulation is discretized and solved within the framework of the finite element method according to the numerical approach detailed in [32], which was successfully used in the simulation of different steel deep drawing processes in [31,32]. Due to the highly non-linear character of the present constitutive model, the solution strategy consists in a two-stage predictor-corrector algorithm incrementally applied at each step of the whole loading sequence. In the predictor stage, a purely elastic response is assumed for both phases ( $m$ and $f$ ). Thus, the strain increments and stress respectively obtained by Equations (5) and (6) are only predictive values that need to be corrected if Equation (8) is not fulfilled, i.e., if plastic effects develop due to the stress level achieved at this loading step. If this is the case, the corrector stage is mainly devoted to update the plastic strain and stress tensors of both phases via the iterative solution of the system of Equations (5)-(9), taking into account the law of mixtures (1) and (2). Finally, the resulting stress tensor obtained with this algorithm is subsequently checked to also fulfill the equilibrium equation in the domain of analysis.

\section{Results}

The microstructure of the ULC, MC and DP0 steels after the heat treatments described in Table 2 are shown in Figure 2. Equiaxial ferrite is observed in Figure 2a after the spheroidization treatment. Although the cementite was not resolved by OM (optical microscopy) observations, it is considered that it will not interact with the mechanical properties of the ferrite. Figure $2 \mathrm{~b}$ shows a mixture of martensite and bainite (dark gray areas). Figure 2c-e display the DP0, DP1 and DP2 microstructures, consisting on a mixture of ferrite (white) and martensite (gray). 


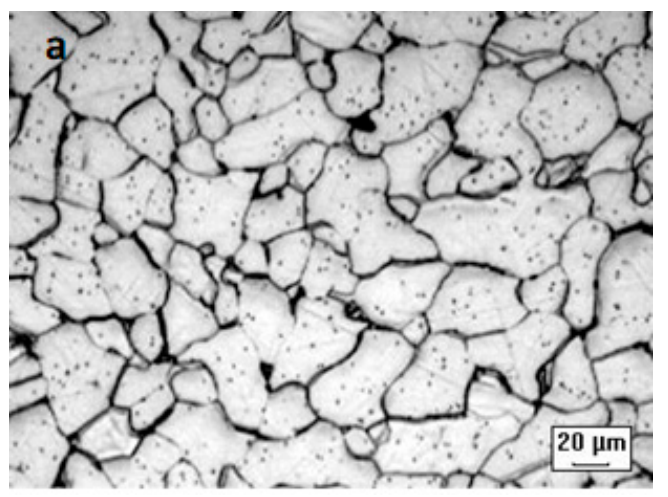

(a)

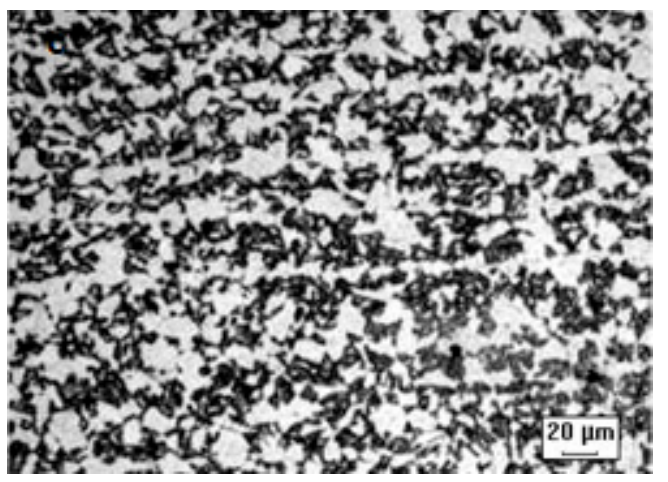

(c)

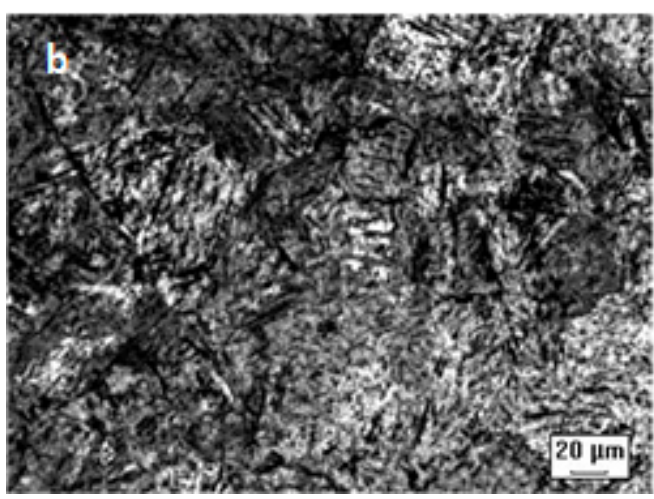

(b)

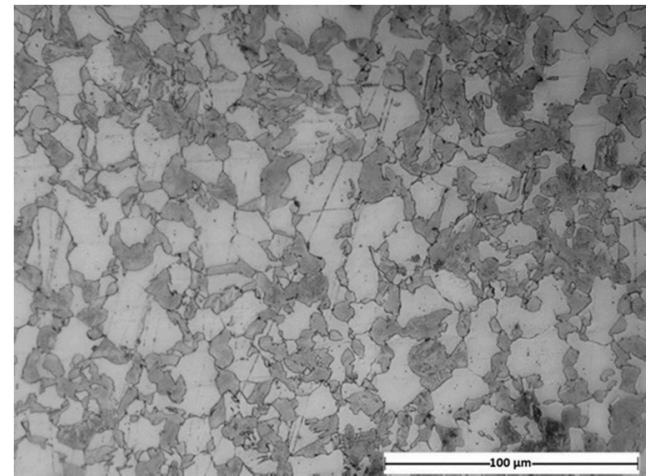

(d)

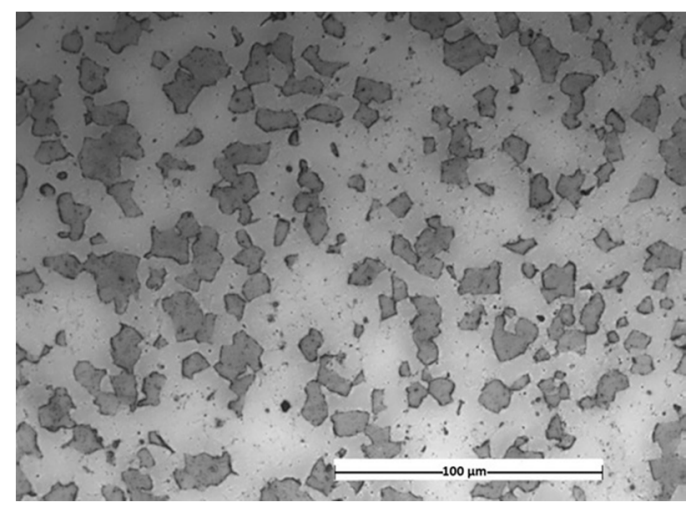

(e)

Figure 2. Optical metallography of (a) ULC, (b) MC and (c) DP0 steels. Etched with Nital 2\%. (d) DP1 and (e) DP2.

The mechanical properties of the ULC, DP1 and DP2 steels were measured via the tensile test. The properties of martensite were determined through Vickers hardness and the relationships introduced by Tabor [34,35] and Krauss [36]. Additionally, Takakuwa applied the Tabor method for the determination of yield stress in stainless steels submitted to surfaces treatments, taking into account residual stresses [37]. The summary of the measured properties is shown in Table 4. Other parameters for the model, such as the Young's and Poisson modules, were considered to be $200 \mathrm{GPa}$ and 0.33 , respectively. The YS (yield strength) of martensite (1570 MPa) was obtained from literature [36]. The experimental stress-strain curve for DP0 showed in Figure 3a was used to calibrate the coefficient $q^{\prime}$. It should be noted that the coefficient $q$ was computed a posteriori from the $q^{\prime}$ values only because $q$ allows a simpler interpretation of the stress and strain phase partitioning since it relates, as stated by Equation (3), total values of stresses and strains (instead of increments as expressed by Equation (4)). 
At the same time, $q^{\prime}$ was also used to model DP1 and DP2 for both the tensile and bending tests. The comparison of the experimental stress-strain tensile curve and the corresponding model predictions for the DP1 and DP2 steels is shown in Figure 3b,c. Additionally, Figure 4 shows the comparison between the experimental and computed results for the force-displacement bending curves for both DP steels.

Table 4. Mechanical properties.

\begin{tabular}{|c|c|c|c|c|c|c|c|}
\hline Steels & YS, MPa & UTS, MPa & YS/UTS & $\begin{array}{c}\text { Elongation } \\
\text { Fracture, }(\%)\end{array}$ & $\mathrm{K}, \mathrm{MPa}$ & n & $\% \mathrm{~m} / \% \mathrm{f}$ \\
\hline ULC-Ferrite & 308 & 369 & 0.83 & 30 & 608 & 0.18 & \\
\hline MC-Martensite & 1570 & 2426 & 0.65 & - & - & - & \\
\hline DP1 $\left(^{*}\right)$ & 488 & 688 & 0.70 & 12.4 & & & 0.59 \\
\hline $\mathrm{DP} 2\left(^{*}\right)$ & 479 & 932 & 0.51 & 7.8 & & & 2.03 \\
\hline
\end{tabular}

* The mechanical properties of the DP steels are indicated here as reference values. It should be noted that they were not used in the constitutive model since the material response of the DP steels was obtained from the mechanical properties of the nearly single steels ULC and MC.

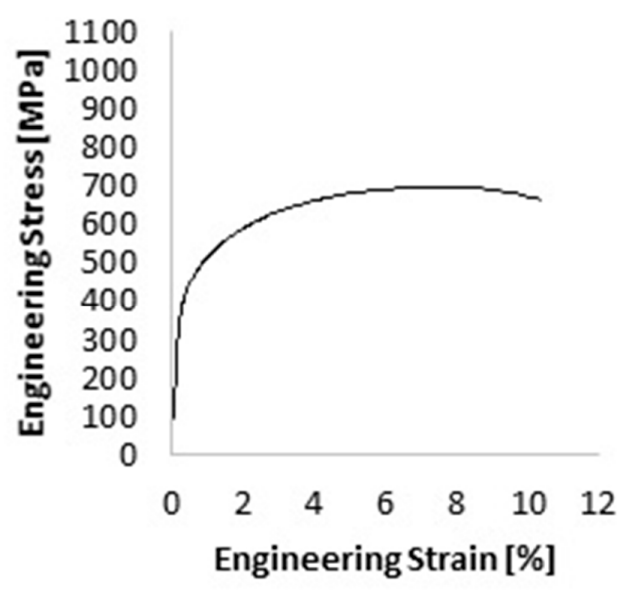

(a)

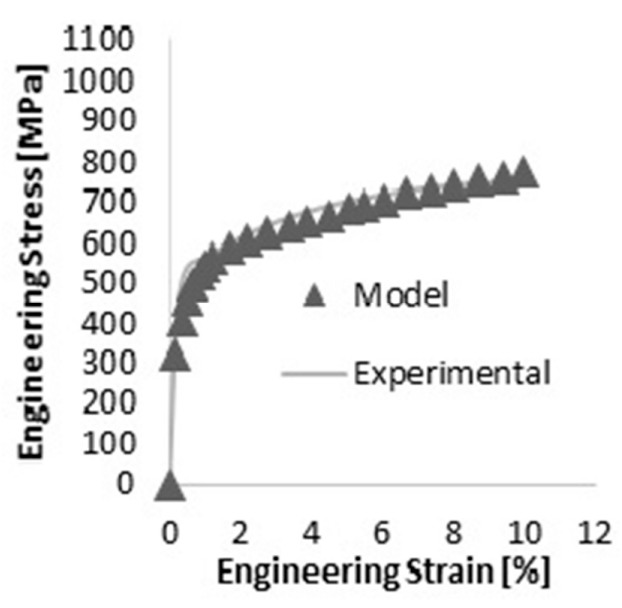

(b)

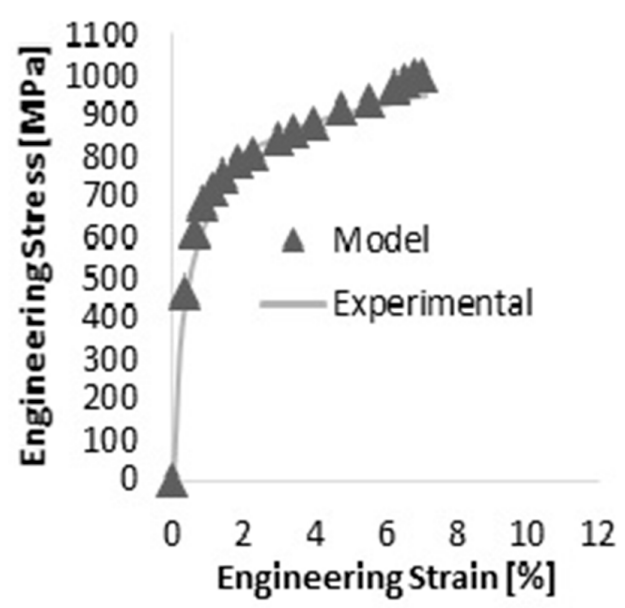

(c)

Figure 3. Experimental and predicted engineering stress-strain curves of (a) DP0, (b) DP1 and (c) DP2 steels. 


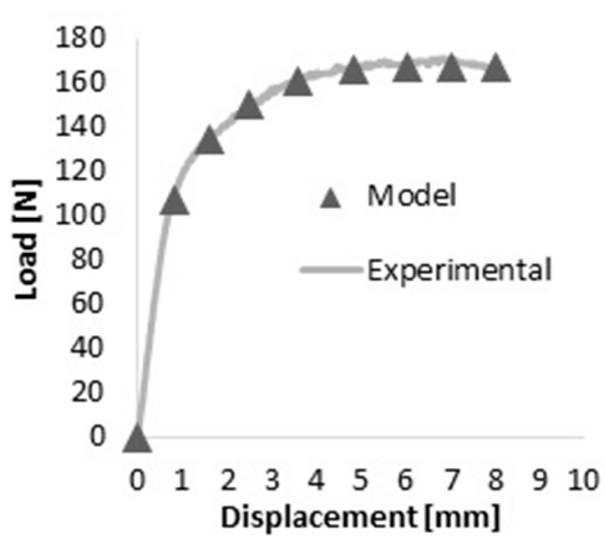

(a)

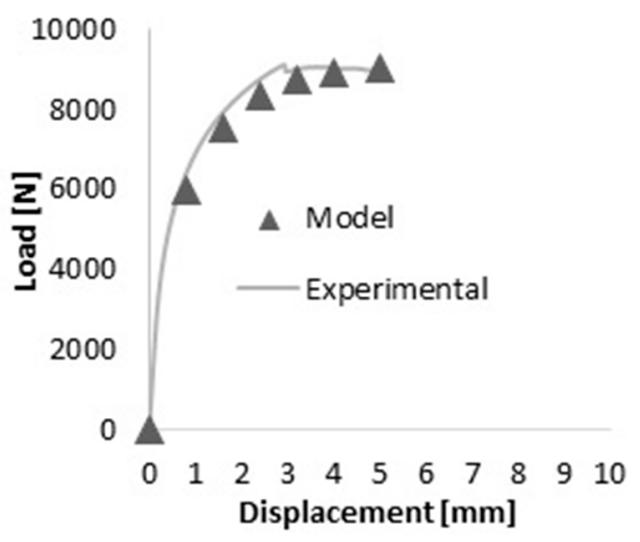

(b)

Figure 4. Experimental and predicted bending force-displacement curves of (a) DP1 and (b) DP2 steels.

YS: Yield Strength; UTS: Ultimate Tensile Strength; K and $\mathrm{n}$ are the Hollomon's parameters; $\% \mathrm{~m} / \% \mathrm{f}$ is the ratio between martensite percentage and ferrite percentage.

\section{Discussion}

\subsection{Microstructure and Mechanical Properties}

The microstructure of the DP steel was considered to be a mixture of ferrite plus martensite. However, the nearly single-phase materials (ULC and MC steels) consist of mixtures of ferrite plus cementite and martensite plus bainite, respectively. Therefore, the mechanical properties measured in the tensile tests are biased by the contribution of these phases and microconstituents. In the case of ULC steel, it was considered that the strength and ductility are negligibly affected by the presence of cementite. The observation of $\sim 3 \%$ bainite, principally at the boundaries of parent austenitic grains, might decrease the strength of the as-quenched martensitic microstructure. One could thus suggest that the deviation of the measured properties with the model just above the YS (Figure 3a) is influenced by the difference in the mechanical properties of martensite (which were calculated assuming that all the austenite was transformed into martensite).

Another clear difference between the initial materials and the DP microstructure is the ferritic and martensitic grain sizes (GS). The grain size dependence of the YS can be described by the Hall-Petch relationship, which predicts that an increase in GS lead to the decrease in the YS. Comparison of Figure 2a,c indicates a considerable difference in GS between the two microstructures and, therefore, one can expect an observable impact in the YS. Similarly, the GS of martensite will have an impact on the YS of the DP steel. However, due to its larger value (compared to ferrite; see Table 4), the effect is neglected.

In the tension tests, the engineering stress does not decrease because the samples do not show necking during the test. Therefore, in all the samples studied, the fracture occurs only with homogenous deformation.

It is observed for DP1 (Figure 3a) that the model slightly underestimates the value of the stress slope at early stages of the homogeneous plastic deformation and fits the measured data in a rather consistent fashion up to a strain value of $10 \%$. The difference stems from the low work-hardening index of the DP steel, which is markedly high up to strains of $\sim 2 \%$. It should be mentioned that the model only considers the implicit dislocation interactions in the ferritic matrix and does not account for the particularities of the ferrite-martensite aggregates. Therefore, the deviations detected at the beginning and last stages of the homogeneous plastic deformation are thus believed to be a consequence of the dislocation interactions not considered within the framework of the proposed model. 
For DP2 steel (Figure 3b), the model fits the measured data reasonably well until a strain value of $8 \%$, when the sample fractures. Heterogeneous deformation was not observed in this sample, so the maximum stress coincides with the fracture stress. It is likely that the brittleness of the sample could be related to the high percentage of martensite that in this sample reaches $67 \%$, as expected.

In both steels, the heterogeneous deformation near the yield stress does not appear due to the martensite phase inducing enough dislocations in the ferrite and permits the plastic deformation evolution in the steels, despite the interactions between carbon atoms and dislocations.

On the other hand, the bending curves of both steels look different due to the different thicknesses of both samples $(0.6$ and $3 \mathrm{~mm})$. It was not possible to reduce the thickness of the DP2 steel by cold rolling and annealing. Apart from this, for both steels, the model fits the experimental data quite well, as shown in Figure 4a,b. It should be mentioned that the mathematical model is based on the parameters derived from the tension test: yield stress, strain hardening coefficients and also the partition coefficient. Therefore, the fact that it is possible to predict the behavior of two DP steels in the tension and bending tests from a mixture rule proves that the model proposed and used in this work is independent of the stress state applied on the solid and, consequently, is of general validity.

\subsection{Other Parameters}

The model determines strain in each phase, and the obtained results show that only the ferrite phase deforms plastically, while martensite remains in the elastic region. The observed difference between the predicted and measured values of YS depends directly on the partition coefficient $q^{\prime}$, which links the material response of each phase (ferrite and martensite) with the effective stress-strain relationship of the DP steel.

The evolution of the partition coefficient $q^{\prime}$ with strain depicted in Figure 5a was obtained by adjusting the model predictions to the experimentally measured engineering stress-strain curves for both the DP1 and DP2 steels. The coefficient $q$ in terms of the true strain plotted in Figure 5b was computed from the results of the simulation with Equation (3), in order to more clearly show the contribution of the martensite and ferrite phases on the effective response of the steels. The sharp slope at small strains, which can be extrapolated to an iso-strain line at the beginning of the plastic deformation, indicates that the material response is mainly governed by the martensite phase during the early deformation stage. At large deformation levels, the decrease in the slope tends to an iso-stress situation for which the behavior of the ferrite phase is predominant in the overall stress-strain curve of the DP steels [15]. In addition, both coefficients $q^{\prime}$ and $q$ are related according to the curve shown in Figure $5 c$. As already mentioned, the parameter adjusted was $q^{\prime}$, while the parameter $q$ was computed a posteriori. The advantage of this last parameter is that it has a clear interpretation on the basis of the stress-strain curves of DP steels and the phases ferrite and martensite.

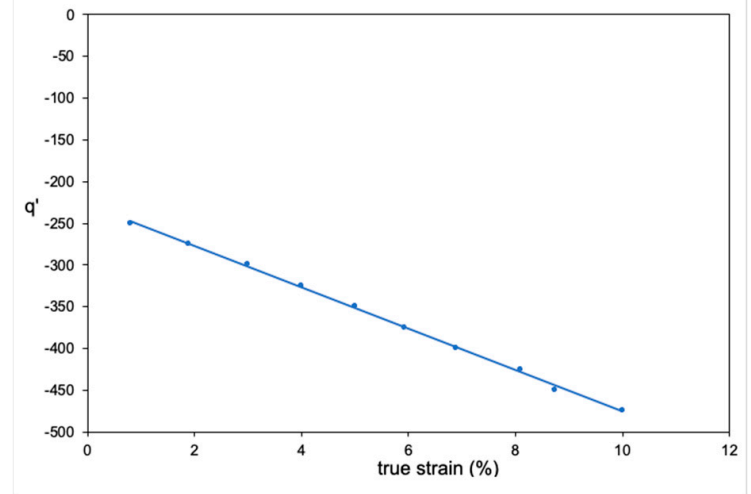

(a)

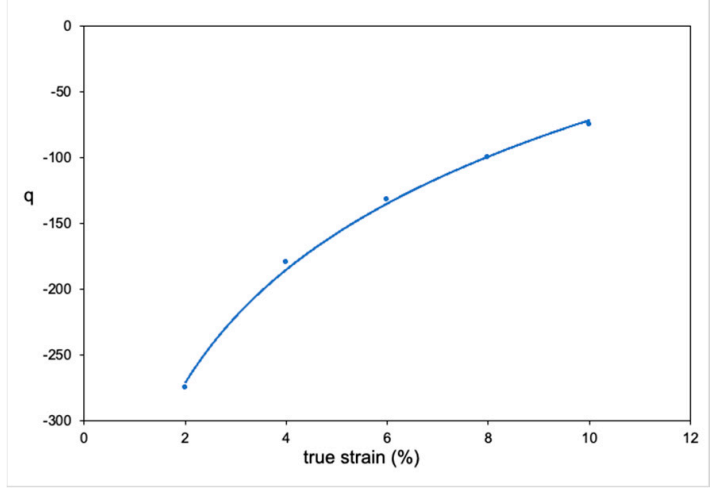

(b)

Figure 5. Cont. 


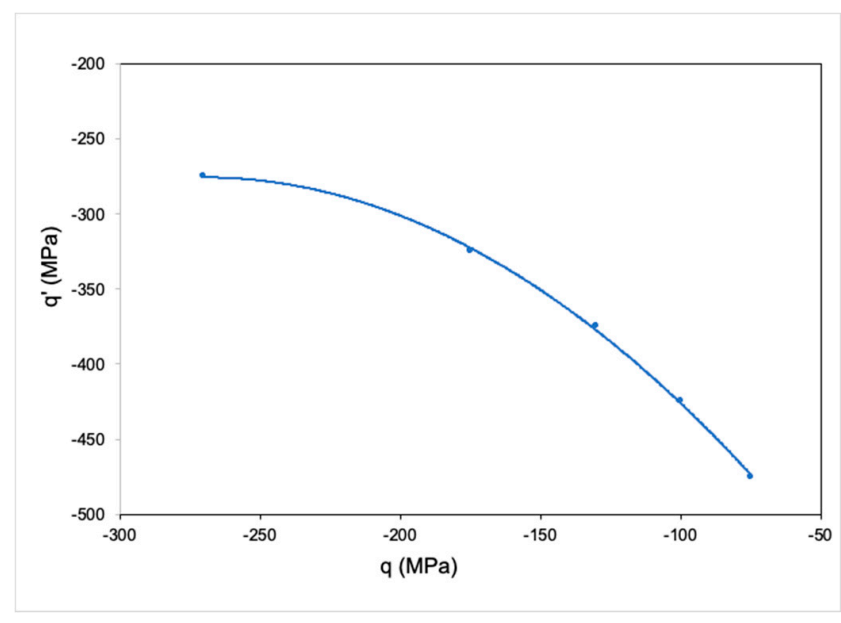

(c)

Figure 5. Dependence of (a) $q^{\prime}$ in terms of the true strain, (b) $q$ in terms of true strain and (c) $q^{\prime}$ in terms of $q$.

When the ferrite phase starts deforming plastically at very small strains, both steels show low yield strength and a very high initial work hardening index, with a YS/UTS factor of 0.70 and 0.51 for DP1 and DP2, respectively. Clearly, the highest strain values are shown by the ferrite phase, while the as-quenched martensite shows only a very limited elastic deformation. This is due to the strain-dependent relationship of the partition coefficient $q^{\prime}$. Therefore, it is possible to conclude that the maximum mechanical strength of the dual-phase steel is not linearly related to the maximum strength of martensite. The experimental values of the stress at high strains, compared with the results of the model, are lower. One possible reason for this might be that the dual phase steel starts to fail at high strain values due to the decohesion of the ferrite and martensite boundaries. To attain a better fit, some failure mode hypotheses should be implemented in the constitutive model.

\section{Conclusions}

In the present study, the mechanical properties of two DP steels were predicted by a constitutive model based on the mechanical properties of individual phases (ferrite and martensite). Two mechanical tests were modeled: tensile and bending. In both cases, a good agreement between experimental data and the model could be observed. The approach considered the tensile measurements of ferrite and martensite and estimated from them the response of the DP steels. A strain-dependent partitioning coefficient relating strain increments with effective stresses was proposed to this end.

The impact on the mechanical properties of the heterogeneities in the initial microstructures was discussed. The grain sizes and bainite fractions, as well as dislocation interactions, which were characteristic of the DP microstructure, were thought to be playing a role at the early stages of homogeneous plastic deformation.

The proposed elastoplasticity model, implemented and solved with finite element-based software, was found to adequately represent the experimental results. It is predicted that, even at the maximum load, the as-quenched martensite has a narrow effect either on the strength or strain of the two DP steels studied in this work.

Author Contributions: Conceptualization, A.M.; data curation, P.A. and F.M.; formal analysis, D.C. and A.M.; funding acquisition, A.M.; investigation, A.A.; methodology, A.A. and A.M.; project administration, A.M.; resources, A.A. and A.M.; software, P.A., F.M. and D.C.; supervision, A.M.; validation, D.C.; visualization, F.M.C.C.; writing - original draft, D.C. and A.M.; writing-review \& editing, D.C., J.-P.P. and A.M. All authors have read and agreed to the published version of the manuscript.

Funding: This research was funded by Direction for Scientific and Technological Research (DICYT), grant number 052014MG, ANID (National Agency of Research and Development) grant number 1180591 and "ANID grant number 111701014". 
Acknowledgments: The authors would like to thank the support provided by Direction for Scientific and Technological Research (DICYT, Dirección de Investigaciones Científicas y Tecnológicas, Grant 052014MG) of Universidad de Santiago de Chile, the Chilean National Found for Science and Technology (FONDECYT, Fondo Nacional de Ciencia y Tecnología) for project 1180591, and “Proyectos Basal USA 1555-Vridei 051714MG_MOV. Universidad Santiago de Chile". F. Castro Cerda gratefully acknowledges the support of ANID, Project No. 111701014.

Conflicts of Interest: The authors declare no conflict of interest.

\section{References}

1. Kot, R.; Morris, J. Symposium on Structure and Properties of Dual-Phase Steels; Metallurgical Society of AIME: Warrendale, PA, USA, 1979.

2. Kot, R.; Bramfitt, B. Symposium on Fundamentals of Dual-Phase Steels; Metallurgical Society of AIME: Warrendale, PA, USA, 1981.

3. Rashid, M. Dual-Phase steels. Annu. Rev. Mater. Res. 1981, 11, 245-266. [CrossRef]

4. Furukawa, T.; Morikawa, H.; Endo, M.; Takechi, H.; Koyama, K.; Akisue, O.; Yamada, T. Process Factors for Cold-rolled Dual-phase Sheet Steels. ISIJ Int. 1981, 21, 812-819. [CrossRef]

5. Shirasawa, H.; Thomson, J.G. Effect of Hot Band Microstructure on Strength and Ductility of Cold Rolled Dual Phase Steel. Trans. Iron Steel Inst. Jpn. 1987, 27, 360-365. [CrossRef]

6. Sugimoto, K.; Usui, N.; Kobayashi, M.; Hashimoto, S. Effects of Volume Fraction and Stability of TRIP-aided of Retained Austenite on Ductility Dual-phase Steels. ISIJ Int. 1992, 32, 1311-1318. [CrossRef]

7. Sugimoto, K.; Misu, M.; Kobayashi, M.; Shirasawa, H. Effects of second Phase Morphology on Retained Austenite Morphology and Tensile Properties in a Trip-Aided Dual-Phase Steel Sheet. ISIJ Int. 1993, 33, 775-782. [CrossRef]

8. Hashimoto, T.M.; Pereira, M.S. Fatigue life studies in carbon dual-phase steels. Int. J. Fatigue 1996, 18, 529-533. [CrossRef]

9. Pouranvari, M. Tensile strength and ductility of ferrite-martensite dual phase steels. Metalurgija 2010, 16, 187-194.

10. Hasegawa, K.; Kawamura, K.; Urabe, T.; Hosoya, Y. Effects of microstructure on stretch-flange-formability of $980 \mathrm{MPa}$ grade cold-rolled ultra high strength steel sheets. ISIJ Int. 2004, 44, 603-609. [CrossRef]

11. El-Sesy, I.A.; El-Baradie, Z.M. Influence carbon and/or iron carbide on the structure and properties of dual-phase steels. Mater. Lett. 2002, 57, 580-585. [CrossRef]

12. Tasan, C.C.; Diehl, M.; Yan, D.; Bechtold, M.; Roters, F.; Schemmann, L.; Zheng, C.; Peranio, N.; Ponge, D.; Koyama, M.; et al. An Overview of Dual-Phase Steels: Advances in Microstructure-Oriented Processing and Micromechanically Guided Design. Annu. Rev. Mater. Res. 2015, 45, 391-431. [CrossRef]

13. Korzekwa, D.; Matlock, D.K.; Krauss, G. Dislocation Substructure as a Function of Strain in a Dual-Phase Steel. Metall. Trans. A 1984, 15, 1221-1228. [CrossRef]

14. Shen, H.; Lei, T.; Liu, J. Microscopic deformation behaviour of martensitic ferritic dual-phase steels. Mater. Sci. Technol. 1986, 2, 28-33. [CrossRef]

15. Kang, J.; Bacroix, B.; Reglé, H.; Oh, K.; Lee, H.C. Effect of deformation mode and grain orientation on misorientation development in a body-centered cubic steel. Acta Mater. 2007, 55, 4935-4946. [CrossRef]

16. Ghadbeigi, H.; Pinna, C.; Celotto, S.; Yates, J. Local plastic strain evolution in a high strength dual-phase steel. Mater. Sci. Eng. A 2010, 527, 5026-5032. [CrossRef]

17. Maire, E.; Bouaziz, O.; Di Michiel, M.; Verdu, C. Initiation and growth of damage in a dual-phase steel observed by X-ray microtomography. Acta Mater. 2008, 56, 4954-4964. [CrossRef]

18. Jiang, Z.; Guan, Z.; Lian, J. Effects of microstructural variables on the deformation behaviour of dual-phase steel. Mater. Sci. Eng. A 1995, 190, 55-64. [CrossRef]

19. Pan, Z.; Gao, B.; Lai, Q.; Chen, X.; Cao, Y.; Liu, M.; Zhou, H. Microstructure and mechanical properties of a cold-rolled ultrafine-grained dual-phase steel. Materials (Basel) 2018, 11, 1399. [CrossRef]

20. Koyama, T. Image-based calculation of stress-strain curve of the two-phase microstructure on the basis of the modified secant method. ISIJ Int. 2012, 52, 723-728. [CrossRef]

21. Liang, J.; Zhao, Z.; Wu, H.; Peng, C.; Sun, B.; Guo, B.; Liang, J.; Tang, D. Mechanical behavior of two ferrite-martensite dual-phase steels over a broad range of strain rates. Metals (Basel) 2018, 8, 236. [CrossRef] 
22. Tomota, Y.; Tamura, I. Mechanical Behavior of Steels Consisting of Two Ductile Phases. ISIJ Int. 1982, 22, 665-677. [CrossRef]

23. Lian, J.; Jiang, Z.; Liu, J. Theoretical model for the tensile work hardening behaviour of dual-phase steel. Mater. Sci. Eng. A 1991, 147, 55-65. [CrossRef]

24. Al-Abbasi, F.M.; Nemes, J.A. Characterizing DP-steels using micromechanical modeling of cells. Comput. Mater. Sci. 2007, 39, 402-415. [CrossRef]

25. Ren, C.; Dan, W.; Xu, Y.; Zhang, W. Effects of heterogeneous microstructures on the strain hardening behaviors of ferrite-martensite dual phase steel. Metals (Basel). 2018, 8, 824. [CrossRef]

26. Liedl, U.; Traint, S.; Werner, E.A. An unexpected feature of the stress-strain diagram of dual-phase steel. Comput. Mater. Sci. 2002, 25, 122-128. [CrossRef]

27. Evin, E.; Kepič, J.; Buriková, K.; Tomáš, M. The prediction of the mechanical properties for dual-phase high strength steel grades based on microstructure characteristics. Metals (Basel) 2018, 8, 242. [CrossRef]

28. Xu, Y.; Dan, W.; Ren, C.; Huang, T.; Zhang, W. Study of the mechanical behavior of dual-phase steel based on crystal plasticity modeling considering strain partitioning. Metals (Basel) 2018, 8, 782. [CrossRef]

29. Celentano, D.J.; Cabezas, E.E.; García, C.M.; Monsalve, A.E. Characterization of the mechanical behaviour of materials in the tensile test: Experiments and simulation. Model. Simul. Mater. Sci. Eng. 2004, 12. [CrossRef]

30. García, C.; Celentano, D.; Ponthot, J.P. Caracterización del comportamiento mecánico de acero para embutición profunda. In Proceedings of the SAM-CONAMET, Bariloche, Argentina, 17-21 November 2003.

31. García, C.; Celentano, D.; Flores, F.; Ponthot, J.P. Numerical modelling and experimental validation of steel deep drawing processes: Part II: Applications. J. Mater. Process. Technol. 2006, 172, 461-471. [CrossRef]

32. García, C.; Celentano, D.; Flores, F.; Ponthot, J.P.; Oliva, O. Numerical modelling and experimental validation of steel deep drawing processes: Part I. Material characterization. J. Mater. Process. Technol. 2006, 172, 451-460. [CrossRef]

33. Hill, R. The Mathematical Theory of Plasticity; Oxford University Press: Oxford, UK, 1998.

34. Tabor, D. A simple theory of static and dynamic hardness. Proc. R. Soc. London A Math. Phys. Eng. Sci. 1948, A 192, 247-274. [CrossRef]

35. Tabor, D. The Hardness of Metals; Clarendon Press: Oxford, UK, 1951.

36. Krauss, G. Martensite in steel: Strength and structure. Mater. Sci. Eng. A 1999, 273-275, 40-57. [CrossRef]

37. Takakuwa, O.; Kawaragi, Y.; Soyama, H. Estimation of the Yield Stress of Stainless Steel from the Vickers Hardness Taking Account of the Residual Stress. J. Surf. Eng. Mater. Adv. Technol. 2013, 3, 262-268. [CrossRef]

(C) 2020 by the authors. Licensee MDPI, Basel, Switzerland. This article is an open access article distributed under the terms and conditions of the Creative Commons Attribution (CC BY) license (http://creativecommons.org/licenses/by/4.0/). 